\title{
Targeted Drug Delivery Systems for Kidney Diseases
}

\author{
Xiaohan Huang ${ }^{1}$, Yanhong Ma', Yangyang $\mathrm{Li}^{2 *}$, Fei Han ${ }^{1 *}$ and Weiqiang $\mathrm{Lin}^{3 *}$ \\ ${ }^{1}$ Key Laboratory of Kidney Disease Prevention and Control Technology, Kidney Disease Center, Zhejiang University School \\ of Medicine, The First Affiliated Hospital, Institute of Nephrology, Zhejiang University, Hangzhou, China, ${ }^{2}$ Key Laboratory \\ of Women's Reproductive Health Research of Zhejiang Province, Women's Hospital, Zhejiang University School of Medicine, \\ Hangzhou, China, ${ }^{3}$ Department of Nephrology, The Fourth Affiliated Hospital, Institute of Translational Medicine, Zhejiang \\ University School of Medicine, Jinhua, China
}

\section{OPEN ACCESS}

Edited by:

Wei Li,

University of Helsinki, Finland

Reviewed by:

Ilaria Arduino,

University of Bari Aldo Moro, Italy

Na Wang,

Johns Hopkins University,

United States

*Correspondence:

Weiqiang Lin

wlin@zju.edu.cn

Yangyang $\mathrm{Li}$

11526010@zju.edu.cn

Fei Han

hanf8876@163.com

Specialty section:

This article was submitted to Biomaterials,

a section of the journal

Frontiers in Bioengineering and

Biotechnology

Received: 20 March 2021

Accepted: 27 April 2021

Published: 28 May 2021

Citation:

Huang X, Ma Y, Li Y, Han F and Lin W (2021) Targeted Drug Delivery

Systems for Kidney Diseases.

Front. Bioeng. Biotechnol. 9:683247.

doi: 10.3389/fbioe.2021.683247
Kidney diseases have gradually become a global health burden. Along with the development of nanotechnology, many hybrids or nanomaterials have been utilized to promote treatment efficiency with negligible side effects. These therapeutic agents have been successfully applied in many fields. In particular, some efforts have also been made to ameliorate the treatment of kidney diseases through targeted delivery nanomaterials. Though most of the delivery systems have not yet been transmitted into clinical use or even still at an early stage, they have shown great potential in carrying immunosuppressants like tacrolimus and triptolide, antioxidants, or siRNAs. Excitingly, some of them have achieved significant treatment effectiveness and reduced systemic side effect in kidney disease animal models. Here, we have reviewed the recent advances and presented nanotherapeutic devices designed for kidney targeted delivery.

Keywords: kidney diseases, nanomaterial, targeted delivery, renal tubules, glomeruli

\section{INTRODUCTION}

The kidney is a vital organ that filters blood and removes excess fluid and waste products. Dysfunction of the kidney may break the fluid and electrolyte balance, and lead to severe problems. However, it can happen undetected until it progressed into advanced stages, so kidney diseases are often considered a silent killer. Common kidney diseases includes IgA nephropathy, membranous nephropathy, acute kidney injury etc. And kidney impairment may also happens secondary to other diseases including diabetes, hypertension and autoimmune diseases. It has been reported that the incidence of chronic kidney disease is reported to be around 11\% (Webster et al., 2017). And according to the US Centers for Disease Control, about 37 million US citizens are estimated to have chronic kidney disease, and nearly 0.7 million are in end-stage kidney disease, needing life-sustaining dialysis or kidney transplant (Centers for Disease Control and Prevention, 2021. Chronic Kidney Disease Surveillance System ${ }^{1}$; Accessed January 7). However, the treatments for kidney diseases are limited. Commonly used medications for kidney diseases including steroids and immunosuppressants tend to have systemic toxicity. Therefore, it is important to improve the safety and efficiency of treatment.

With the development of nanotechnology, a variety of hybrids, including nanoparticle-platformbased therapeutic agents, have emerged. Medical investigators have gradually realized that

\footnotetext{
${ }^{1}$ https://nccd.cdc.gov/CKD
} 
nanotechnology might contribute potential advances to basic medical research and clinical practice (Zhou et al., 2014; Kamaly et al., 2016; Liu et al., 2019). The nanoparticle-based drug delivery platform enables therapeutic agents can specifically accumulate at diseased sites (Blanco et al., 2015), and thus reduce undesired systemic effects. Also, targeting specific components of the kidney may provide new approaches to refractory diseases. For example, targeting tubular cells to reduce fibrosis, and targeting mesangial cells to ameliorate mesangial proliferative glomerulonephritis.

Here we present recent developments of nanoparticles designed for kidney targeted delivery and briefly introduce targeting strategies for the kidney (Table 1).

\section{TARGETED DELIVERY FOR RENAL TUBULOINTERSTITIAL DISEASES}

\section{Targeting Strategies}

Renal tubules include the proximal tubule, the loop of Henle, the distal tubule, and the collecting ducts. Renal tubulointerstitial injuries including renal interstitial inflammation or fibrosis and tubular atrophy are the common result of kidney diseases and are crucial in the development of chronic kidney disease and end-stage kidney diseases. They can occur secondary to vascular and glomerular diseases, or primary tubulointerstitial diseases, for example, acute kidney injury (Dolman et al., 2010; Grgic et al., 2012; Falke et al., 2015; Ramos et al., 2015). Overactivated immune system and oxidative stress play important roles in the pathogenesis of the diseases.

Proximal tubule targeted therapeutics including inhibitors of the renin-angiotensin-aldosterone system, steroids, and immunosuppressants can be promising drugs to inhibit tubulointerstitial fibrosis and prevent the progression of chronic renal diseases (Dolman et al., 2010; Falke et al., 2015). And antioxidants targeting renal tubules may protect the tubular cells from ROS- induced oxidative stress (Wang et al., 2021).

Various forms of nanomaterials have been used to design drug carriers (Figure 1; Senapati et al., 2018). To target renal tubules, surface chemistry, size, and charge can be important factors.

\section{Size, Charge, and Surface Chemistry}

The fenestration of the peritubular capillary is sized $60-70 \mathrm{~nm}$ (Dolman et al., 2010). And the glomerular filtration barrier in a healthy kidney is negatively charged with slits at about 6-10 nm (Oroojalian et al., 2020). The barrier allows small molecules with diameters less than $6 \mathrm{~nm}$ (including NPs with high aspect ratios but small diameters, for example, rods, tubes, and sheets) to pass through (Figure 2; Park et al., 2008; Chauhan et al., 2011; Jasim et al., 2016). Of note, though some small NPs sized less than $10 \mathrm{~nm}$ or proteins smaller than $20 \mathrm{kDa}$ can distribute at tubules, they may not be able to retain in the body (Dolman et al., 2010).

Due to charge selectivity (Comper and Glasgow, 1995), NPs with negative surface charges are more likely to be blocked out by the filtration barrier (Choi et al., 2009). But interestingly, some studies found that strongly negatively charged NPs may pass the barrier faster than weakly negatively charged or positively charged NPs in some situations, and thus further investigation
TABLE 1 | Nanomaterials for kidney targeted drug delivery.

\begin{tabular}{|c|c|c|c|}
\hline Target & Material & Particles & References \\
\hline Tubules & PLGA & $\begin{array}{l}\text { Mesoscale nanoparticles } \\
\text { (MNPs) PLGA-PEG }\end{array}$ & $\begin{array}{l}\text { Williams et al., } \\
\text { 2015, 2018; Deng } \\
\text { et al., 2019; He } \\
\text { et al., } 2020\end{array}$ \\
\hline Tubules & PLGA, ceria & $\begin{array}{l}\text { Ceria nanoparticles } \\
\text { modified with } \\
\text { triphenylphosphine } \\
\text { (TCeria NPs) and coated } \\
\text { with ROS-responsive } \\
\text { organic polymer }\end{array}$ & Yu et al., 2020 \\
\hline Tubules & Chitosan & $\begin{array}{l}\text { Chitosan/siRNA } \\
\text { nanoparticles mediated } \\
\text { by megalin dependent } \\
\text { endocytic pathway }\end{array}$ & $\begin{array}{l}\text { Gao et al., 2014; } \\
\text { Yang et al., } 2015\end{array}$ \\
\hline Tubules & Chitosan & $\begin{array}{l}\text { Catechol-derived low } \\
\text { molecular weight } \\
\text { chitosan }\end{array}$ & Luo et al., 2019 \\
\hline Tubules & Chitosan & $\begin{array}{l}\text { Catechol-derived low } \\
\text { molecular weight } \\
\text { chitosan }\end{array}$ & $\begin{array}{l}\text { Qiao et al., 2014; Li } \\
\text { et al., } 2017\end{array}$ \\
\hline Tubules & Chitosan, PLGA & $\begin{array}{l}\text { MicroRNA inhibitor- } \\
\text { LMWC-modified PLGA } \\
\text { nanoparticles }\end{array}$ & Geng et al., 2018 \\
\hline Tubules & Chitosan & $\begin{array}{l}\text { I-serine-modified } \\
\text { chitosan -TK-SS31 }\end{array}$ & Liu et al., 2020 \\
\hline Tubules & PAMAM & $\begin{array}{l}\text { PAMAM dendrimer-based } \\
\text { macromolecular } \\
\text { conjugate of a } \\
\text { multitargeted sunitinib } \\
\text { analog }\end{array}$ & $\begin{array}{l}\text { Dolman et al., } \\
\text { 2012b }\end{array}$ \\
\hline Tubules & PAMAM & $\begin{array}{l}\text { I-Serine modified PAMAM } \\
\text { dendrimers }\end{array}$ & $\begin{array}{l}\text { Matsuura et al., } \\
\text { 2018a,b; Katsumi } \\
\text { et al., } 2019\end{array}$ \\
\hline Tubules & $\mathrm{pSi}$ & $\begin{array}{l}\text { pSi NP displaying with } \\
\text { monoclonal antibodies } \\
\text { loaded with rapamycin }\end{array}$ & $\begin{array}{l}\text { Stead et al., 2018; } \\
\text { Zhang et al., } 2019\end{array}$ \\
\hline Tubules & Protein & $\begin{array}{l}\text { DNA-binding protein from } \\
\text { starved cells (Dps) }\end{array}$ & Uchida et al., 2019 \\
\hline Glomeruli & $\begin{array}{l}\text { Liponanoparticles, } \\
\text { peptide }\end{array}$ & $\begin{array}{l}\text { Kidney-targeted rhein } \\
(\mathrm{RH}) \text {-loaded } \\
\text { liponanoparticles (KLPPR) }\end{array}$ & Wang et al., 2019 \\
\hline Glomeruli & Antibody & $\begin{array}{l}\text { Human monoclonal } \\
\text { anti- } \alpha 3(\mathrm{IV}) \text { antibody }\end{array}$ & Bruni et al., 2017 \\
\hline Glomeruli & Antibody & $\begin{array}{l}\text { Anti-VCAM-1-rapamycin- } \\
\text { SAINT-O-Somesthat }\end{array}$ & $\begin{array}{l}\text { Visweswaran et al., } \\
2015\end{array}$ \\
\hline Glomeruli & $\begin{array}{l}\text { PHMAM, } \\
\text { peptide }\end{array}$ & $\begin{array}{l}\text { PHMAM copolymer } \\
\text { integrin } \alpha \text { V } \beta 3 \text {-specific } \\
\text { cyclo-RGD }\end{array}$ & $\begin{array}{l}\text { Pollinger et al., } \\
2012\end{array}$ \\
\hline Glomeruli & Gold & PEGylated gold NPs & Choi et al., 2011 \\
\hline Glomeruli & $\begin{array}{l}\text { Antibody, } \\
\text { liposomes }\end{array}$ & $\begin{array}{l}\text { Immunoliposomes } \\
\text { coated with } \\
\text { anti-integrin } \alpha 8 \\
\text { monoclonal antibodies or } \\
\text { anti-Thy-1-membrane } \\
\text { glycoprotein (Thy1) }\end{array}$ & $\begin{array}{l}\text { Scindia et al., 2008; } \\
\text { Suana et al., } 2011\end{array}$ \\
\hline Glomeruli & $\begin{array}{l}\text { Peptide, } \\
\text { liposomes }\end{array}$ & $\begin{array}{l}\text { PEG-modified liposome } \\
\text { with desired size ( } 110 \\
\mathrm{~nm} \text { ) and octa-arginine } \\
\text { (R8) coating }\end{array}$ & Wang et al., 2020 \\
\hline
\end{tabular}

PLGA, Poly(lactic-co-glycolic acid); PAMAM, Polyamidoamine; pSi, porous silicon; PHMAM, Poly(N-2hydroxypropyl)meth acrylamide; PEG, polyethylene glycol; NP, nanoparticles; CaPi, calcium phosphate; LWMC, low molecular weight chitosan. 


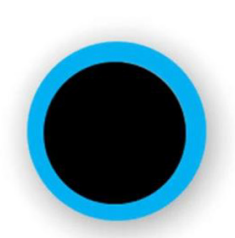

0-D Material

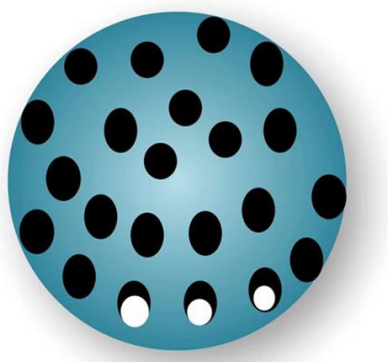

Mesoporous

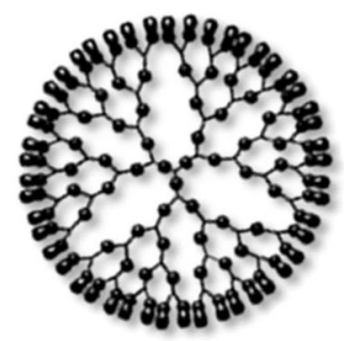

Dendrimer

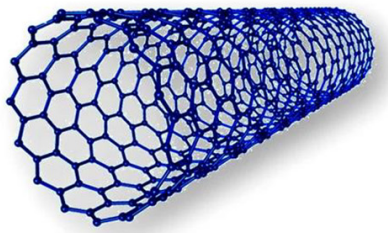

1-D Material

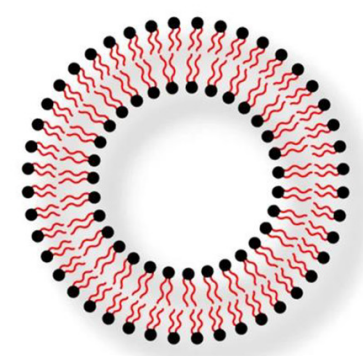

Liposome

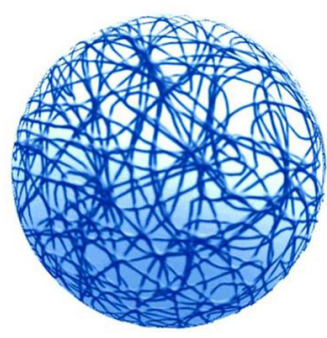

Polymeric nanoparticles

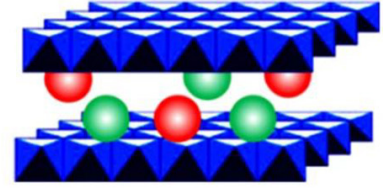

2-D Material

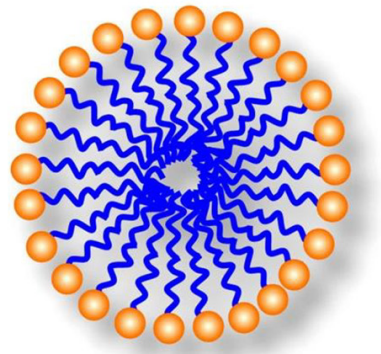

Micelle

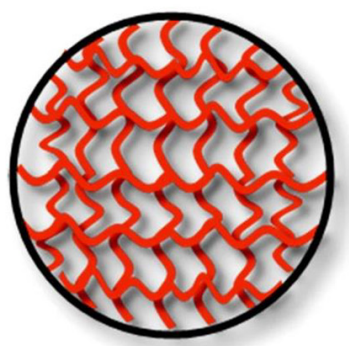

Hydrogel

FIGURE 1 | Different types of nanocarriers. Reproduced with permission (Senapati et al., 2018).

should be provided to prove detailed discussion (Kang et al., 2016; Yu et al., 2017). High dose of NPs with positive surface charge may have cytotoxicity due to disturbtion to resting potential.

Surface modification may affect organ distribution (Amin et al., 2015; Kokkinopoulou et al., 2017). Before reaching kidney tissues, NPs should try to reduce the chance of absorbing serum proteins which may form protein corona (Salvati et al., 2013; Jiang et al., 2018; Richtering et al., 2020) and avoid being captured by the reticuloendothelial system of the liver (slits about 50$100 \mathrm{~nm}$ ), the spleen (slits about 200-500 nm), or other organs (Klibanov et al., 1990; Du et al., 2017; Sun et al., 2017). It has been suggested that surface modifications like polyethylene glycol (PEG) molecules can reduce serum protein adsorption, and thus avoid being captured by the reticuloendothelial system (Harris and Chess, 2003; He et al., 2011). Meanwhile, the negatively charged surface will help to decline the formation of protein corona in vivo (Alexis et al., 2008; Blanco et al., 2015).

In the diseased situation, both the size and surface charge control of the barrier can be impaired (Pavenstädt et al., 2003; Du et al., 2018), allowing particles with larger sizes to pass through. Still, it should avoid being captured by the liver, spleen, or other organs. Of note, in kidney diseases, inflammation usually leads to acidosis at diseased sites, and thus $\mathrm{PH}$ triggered systems can be used to design targeted delivery systems.

\section{Molecular Recognition and Endocytosis}

Molecular recognition moiety, including antibody, small molecule, or aptamer, can be used as another strategy. These moieties can be recognized by certain surface receptors and thus binds to renal cells. For example, drugs containing certain surface molecules can achieve kidney-targeted delivery through Megalin/cubilin-mediated endocytosis (Figure 3) by the luminal membrane of tubular epithelial cells (Williams et al., 2016). Megalin is a low-density lipoprotein (LDL) receptor that is expressed in epithelial cells of the intestine, kidney, and other tissues (Christensen and Birn, 2002; Nielsen et al., 2016). On the apical plasma membrane of proximal tubule cells, it binds with cubilin (intestinal intrinsic factor-cobalamin receptor) and can mediate the endocytosis of many ligands including lipoproteins, hormones, enzymes, lysozyme, carrier proteins, drugs (such as aminoglycoside and polymyxin B and chitosan) (Christensen and Birn, 2002; Lin et al., 2013; Oroojalian et al., 2017; Xu et al., 2020). 


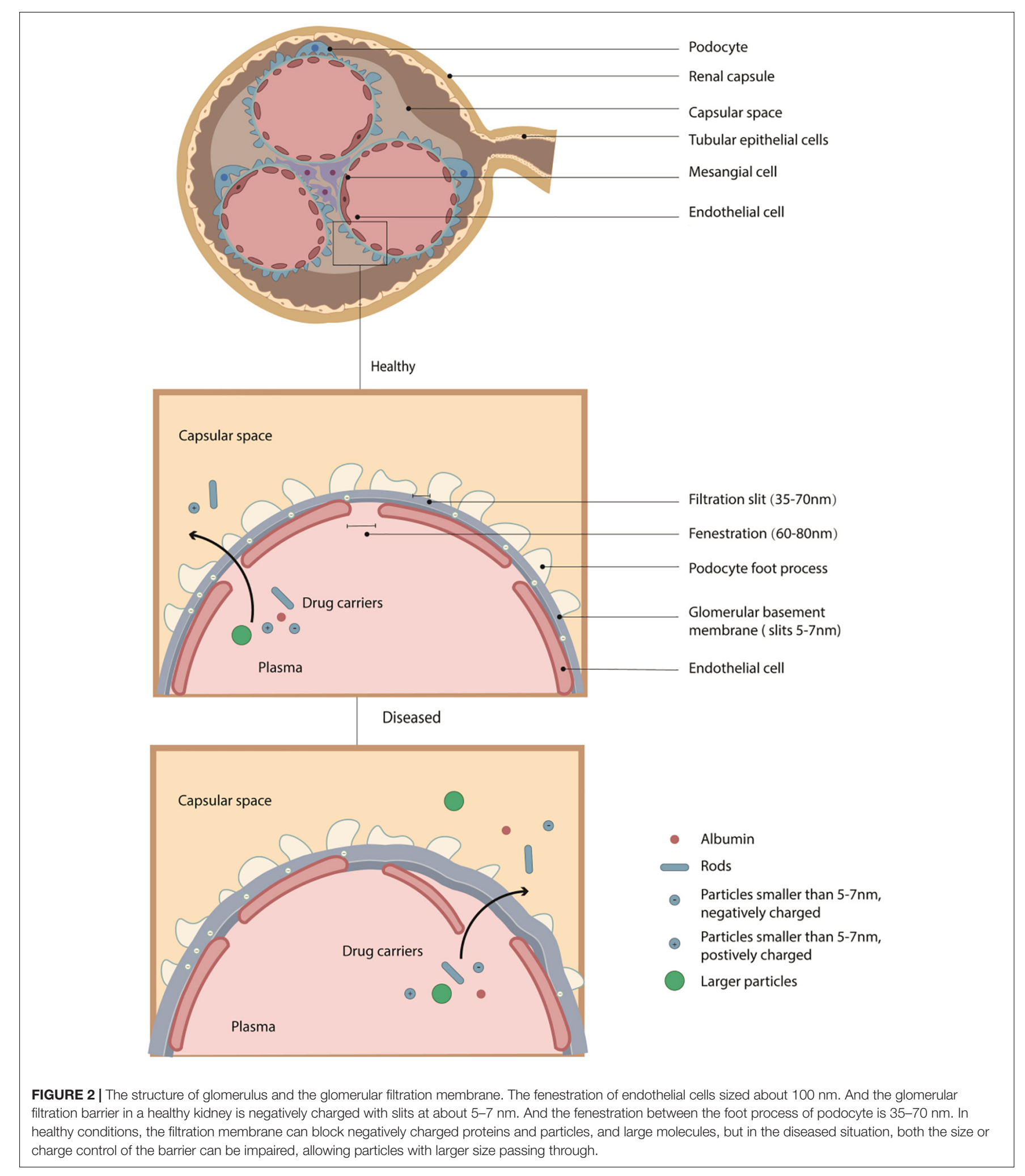

It is one of the most important pathways for the absorption of many molecules and tubular targeting NPs in renal tubular cells. (KKEEE) ${ }_{3} \mathrm{~K}$ (Lys-Lys-Glu-Glu-Glu]3-Lys) is one of the well-studied peptide ligands that can achieve targeted kidney delivery through megalin-mediated endocytosis of proximal tubule cells (Wang et al., 2018). Variations of (KKEEE) 3K peptides possess targeting performance for the kidney (Janzer et al., 2016; Wischnjow et al., 2016; Huang et al., 2020). 


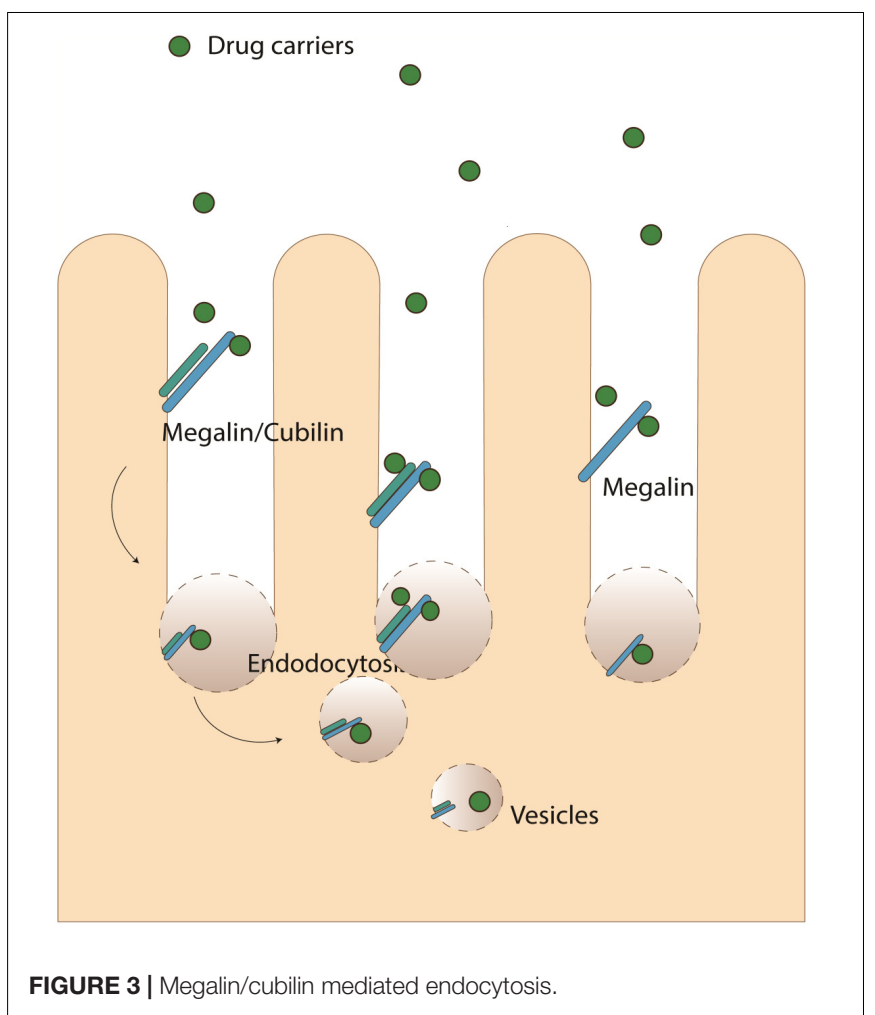

\section{Drug Delivery Systems for Renal Tubules PLGA-PEG NPs}

Poly(lactic-co-glycolic acid) (PLGA) conjugated to polyethylene glycol (PEG) is one of the most commonly used polymers to synthesize polymeric NPs (Danhier et al., 2012). The Biosafety of PLGA-PEG has been well-tested and its application in humans has been approved by the FDA. Mesoscale nanoparticle (MNP) is about $400 \mathrm{~nm}$ in diameter and is a drug delivery system formed from PLGA-PEG (Williams et al., 2015). By intravenous administration, it can specifically localize at the kidneys (7 times than other organs) and retain in renal epithelial cells for weeks (Williams et al., 2015). The particles can be released to the tubulointerstitium after being endocytosed by peritubular endothelial cells and then uptake by tubular epithelial cells. The capacity of kidney-specific accumulation is dependent on the size and hydrophilic PEG surface while the surface charge does not affect its targeting effect (Williams et al., 2015). The long PEG chains can reduce opsonization and thus avoid been captured by the mononuclear phagocyte system. Mice treated with MNPs displayed primarily tubular localization without obvious side effects (Williams et al., 2018). For the treatment of renal diseases, a research group has successfully constructed triptolide-encapsulated MNPs (TP-MNP). Triptolide is an immunosuppressant and the TP-MNPs showed kidneyspecific accumulation and high treatment efficiency in the ischemia-reperfusion AKI animal model (Deng et al., 2019).

PLGA-PEG nanoparticles modified by kidney targeting proteins (KTP) can achieve 30-fold enhanced targeted delivery of Asiatic acid (an anti-inflammatory drug) to renal tubules, and can potentially be used in the treatment of chronic kidney diseases (He et al., 2020). However, this NP carreier may also slightly enhance drug distribution in heart.

\section{Chitosan-Based NPs}

Chitosan is another widely used NP material for its great biocompatibility and biodegradability (Narayanan et al., 2014; Kravanja et al., 2019). Chitosan/siRNA nanoparticles also can target siRNA at the tubular cells in mice (Gao et al., 2014; Yang et al., 2015). The uptake was mediated by a megalin-dependent endocytic pathway (Gao et al., 2014). Low molecular weight chitosan-based NPs can increase the uptake by renal tubular cells (Luo et al., 2019). Qiao et al. (2014) designed an NP based on hydrocaffeic acid-containing catechol-derived low molecular weight chitosan (HCA-Chi) and metal ions also showed special renal targeting capacity (Figure 4). The distribution of HCAChi outside the kidneys are neglitable. And when loaded with emodin (an antifibrosis agent), the NP can inhibit the progression of renal fibrosis in ureter obstructed mice (Qiao et al., 2014). Also, HCA-Chi modified with calcium and salvianolic acid B reversed the TGF- $\beta 1$-induced epithelial-mesenchymal transition in HK2 cells (an immortalized proximal tubule epithelial cell line), and in vivo imaging showed a kidney-specific biodistribution (Li et al., 2017). Small-sized cationic microRNA inhibitor- LMWCmodified PLGA nanoparticles also possess kidney-targeting capability and high antifibrosis efficiency (Geng et al., 2018). The drug is two times higher in kidney than heart or liver.

A research team from Korea synthesized hydrophobically modified glycol chitosan (HGC) polymeric nanomicelles, and when loaded with tacrolimus, the hybrid showed efficient selective delivery to the kidney and can significantly reduce systemic side effect (Kim et al., 2020). Liu et al. (2020) designed 1-serine-modified chitosan-based carrier (SC) and found that it can effectively accumulate at kidney in AKI mice while been cleared by healthy mice (Figure 5). And when ROS-sensitive prodrugs (SS31) were conjugated with the carrier, the drug (SCTK-SS31) was successfully distributed in tubular cells and showed enhanced protective effect from AKI (Liu et al., 2020).

\section{Dendrimers}

Polyamidoamine (PAMAM) dendrimer-based NPs are another group of extensively studied drug delivery NPs. Dendrimers are globular macromolecules with highly branched structures that enable efficient conjugation of targeting ligands (Figure 6; Gillies and Frechet, 2005; Abbasi et al., 2014; Huang and $\mathrm{Wu}, 2018)$. Several studies demonstrated that I-Serine modified PAMAM (G3) dendrimers are highly potent as a renal proximal tubule- targeted drug carrier (Matsuura et al., 2018a,b; Katsumi et al., 2019) as it accumulates mainly in the kidney and the level in other organs are neglitable. The NPs can be used to prevent ischemia/reperfusion kidney injury as reactive oxygen species (ROS) scavenger. The dendrimers can be filtered by the filtration membrane and be reabsorbed by tubular cells. The mechanism of reabsorption involves caveolaemediated endocytosis, micropinocytosis, and megalin-mediated endocytosis (Matsuura et al., 2018b). Researchers have found that a high degree of Ser modification $(\geq 80 \%)$ was required 


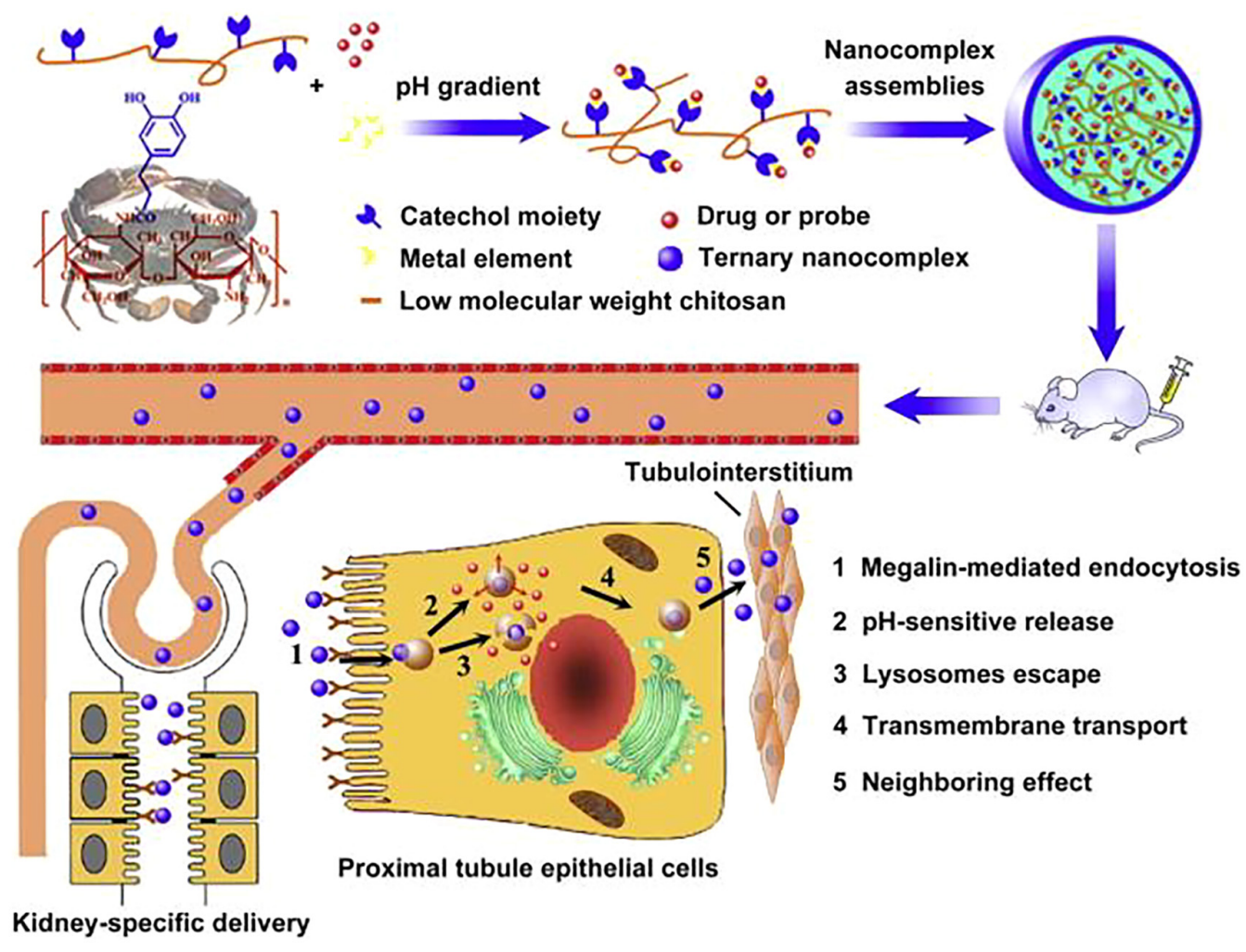

FIGURE 4 | HCA-Chi for kidepH-response nanodevice based on a coordination-driven assembly of HCA-Chi for sequential and kidney-specific drug delivery. Reprinted with permission (Qiao et al., 2014).

for effective kidney-specific delivery (Matsuura et al., 2018b). The dendrimer can effectively deliver captopril to the kidney (Matsuura et al., 2018a) and thus reduce its side effects. PAMAM dendrimer-based macromolecular conjugate of a multitargeted sunitinib analog also showed proximal tubular cell-targeted delivery (Dolman et al., 2012b). The sunitinib analog is conjugated to $\mathrm{NH}(2)$-PAMAM-G3 dendrimer with a platinumbased linker and displayed efficient accumulation in rodent kidneys. Besides, the same group conjugate the sunitinib analog to a kidney-specific carrier lysozyme, with antifibrotic effects (Dolman et al., 2012a), suggesting lysozymes can also be used as a targeting ligand (Kamaly et al., 2016).

\section{NPs Displaying Antibodies}

Porous silicon ( $\mathrm{pSi}$ ) NPs are a nanomaterial with versatile surface modification routes and can be used in controlled drug delivery (Zhang et al., 2019). A pSi NP displaying monoclonal antibodies loaded with rapamycin showed enhanced kidney targeting (Stead et al., 2018). Though originally designed to promote regulatory $\mathrm{T}$ cell proliferation, it may serve as a potential treatment for Fanconi syndrome, which is a disease of renal proximal tubules (Stead et al., 2018; Zhang et al., 2019).

\section{Other NPs Targeting Renal Tubules}

Ultra-small ceria nanoparticles modified triphenylphosphine (TCeria NPs) and coated with
ROS-responsive organic polymer (mPEG-TK-PLGA) can target mitochondria. Kidney and liver are the main accumulation sites in healthy mice and the accumulation in kidney is significantly higher in AKI mice. When loaded with atorvastatin can protect tubular cells from oxidative stress and inflammation in AKI mice models (Yu et al., 2020). However the toxicity of TCeria should be awared.

DNA-binding protein from starved cells (Dps), cage-like protein nanoparticles that are sized less than $9 \mathrm{~nm}$, can pass through the glomerular filtration barrier to be endocytosed by proximal tubules. Its accumulation in other oragans are neglitable comparing to that in the kidney. And based on its characteristics, modified Dps can be a platform targeting renal proximal tubules. Researchers have found that manganese-bound Dps (MnDps) can act as an antioxidant and protect the kidney from endotoxin-induced injury in mice (Uchida et al., 2019).

\section{DRUG DELIVERY SYSTEMS FOR GLOMERULAR DISEASES}

\section{Targeting Strategy for Glomeruli}

The glomerulus contains mesangial cells, parietal epithelial cells, visceral epithelium cells (podocyte), glomerular basement membrane (GBM), and glomerular endothelial cells (GEC) 
A

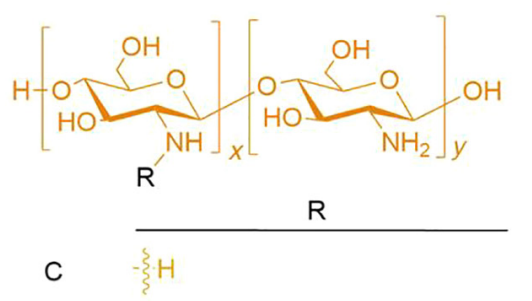

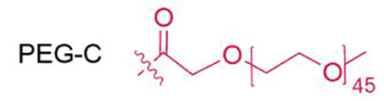

S-PEG-C<smiles>[14CH2][14C](=O)C(N)O</smiles>
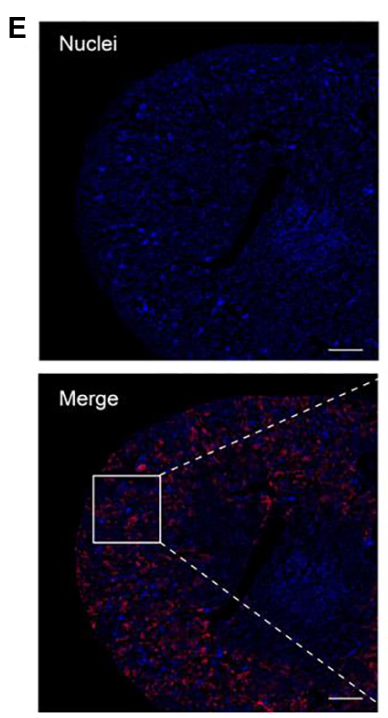

B
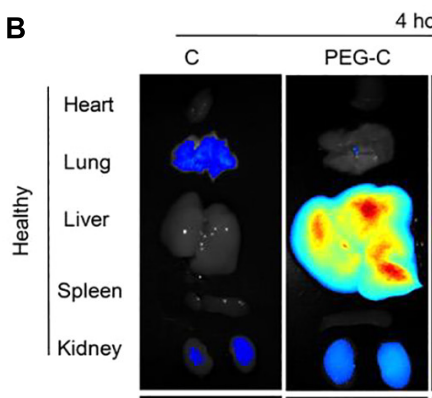

ours
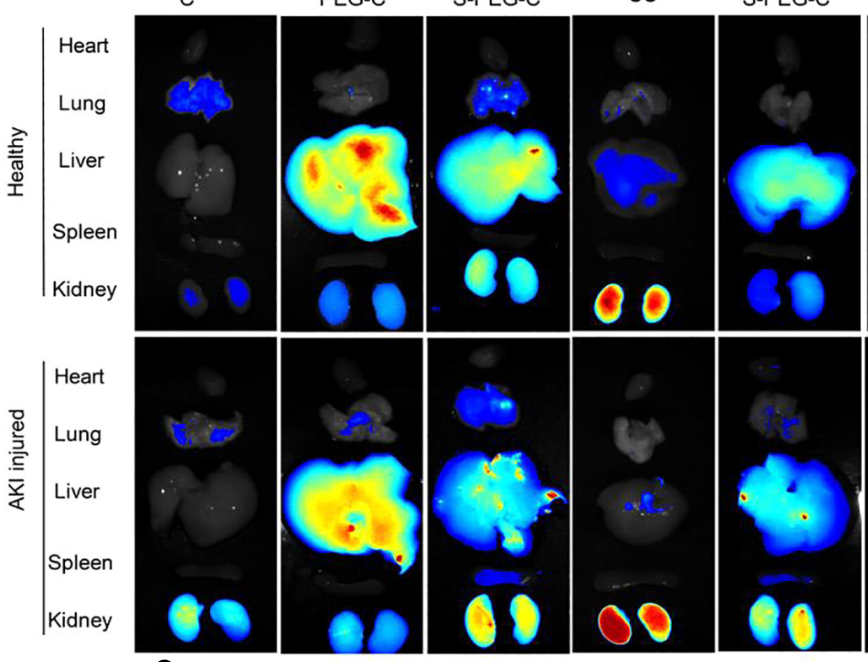

SC
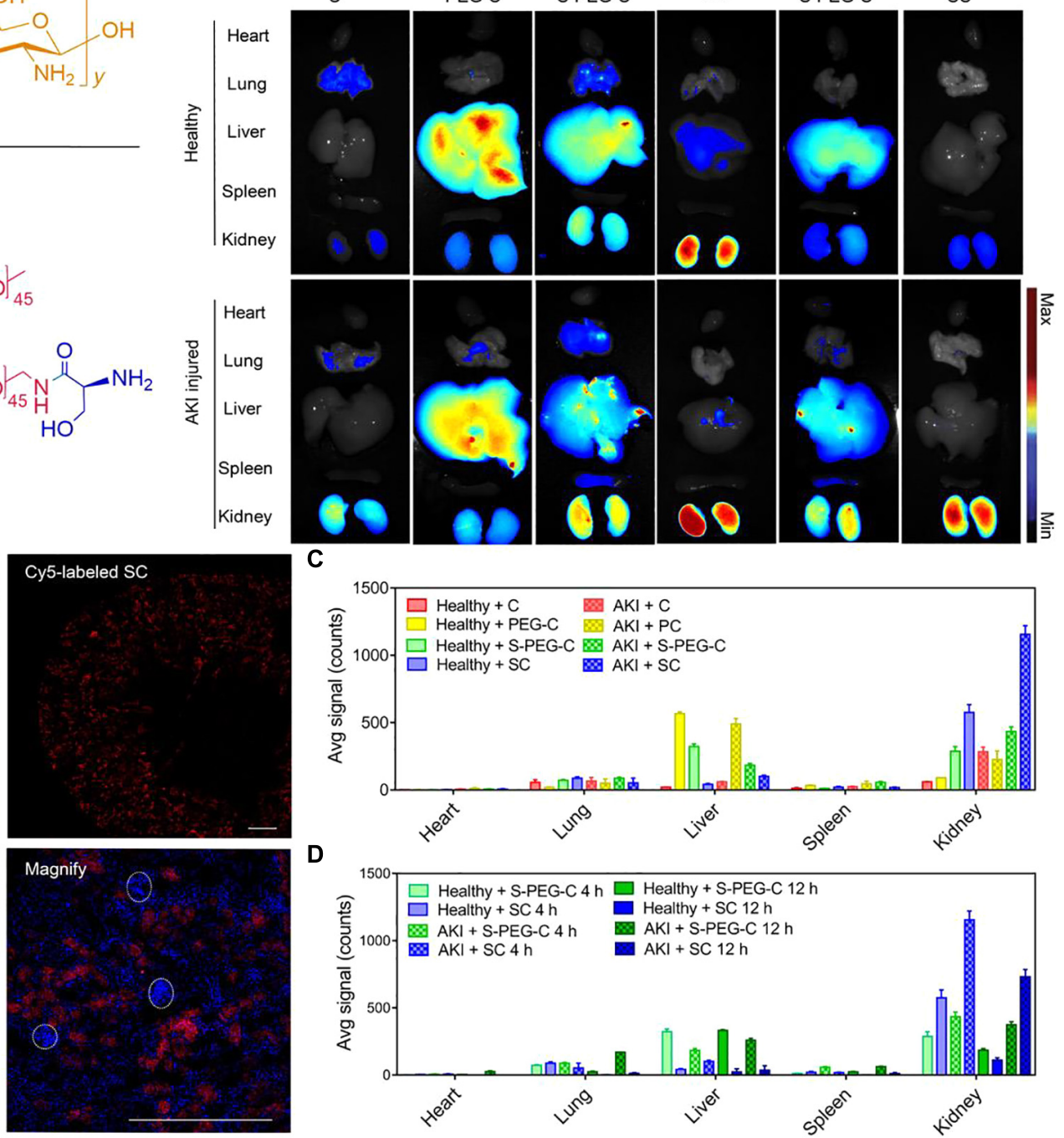

FIGURE 5 | Renal distribution and renal tubules accumulation of I-serine-modified chitosan (SC). Reprinted with permission (Liu et al., 2020). (A) The chemical structures of SC and its analogies (B) Fluorescence images of the main organs (heart, lung, liver, spleen, and kidney) of mice at 4 or $12 \mathrm{~h}$ after intravenous injection of Cy5-C, Cy5-PEG-C, Cy5-S-PEG-C, or Cy5-SC. One of three independent experiments is shown. Renal ischemia was induced by clamping of the bilateral renal pedicles for 30 min and then removed clamping to induce IR AKI. After the initiation of AKI, fluorescence-labeled SC and its analogies were administered intravenously. Four or twelve hours later, the main organs were harvested for fluorescence visualization. The healthy mice were treated with the same protocol as control. (C,D) Region of interest analysis of the kidney uptake at 4 and $12 \mathrm{~h}$ after injection. The data are the means \pm SD. $n=3$ independent mice.

(E) Representative confocal images of kidney sections after intravenous injection of Cy5-SC (red signal) for 4 h. Blue indicates 4 ',6-diamidino-2-phenylindole (DAPI) staining. White dashed circles denote glomeruli. Scale bars, $500 \mu \mathrm{m}$.

(Haraldsson et al., 2008; Jarad and Miner, 2009; Lu and Gu, 2017; Zhao, 2019). And the later three forms the glomerular filtration barrier.

Glomerular diseases are the most common form of kidney diseases. The inflammation of glomeruli is called glomerulonephritis, common forms of glomerulonephritis and cellular location of their injury are listed in Table 2 (Chadban and Atkins, 2005). The pathogenesis of glomerulonephritis usually involves the deposition of abnormal immunocomplexes and overactivation of immune cells. Thus, steroids and immunosuppressants including mycophenolate mofetilare, celastrol, tacrolimus, cyclophosphamide and cyclosporin are the most common therapeutics for glomerular diseases.

Currently, limited methods can be used to target glomeruli. Similar to the targeting strategy of renal tubules, size, shape, and especially molecular recognition moiety is important in glomeruli-specific delivery. Of note, diseased glomeruli expose epitopes that are usually sequestered, and thus enhances antibody-mediated targeted delivery. And some surface molecules are upregulated in diseased conditions and thus provide targeting sites for carriers. Renal targeting peptide ligands and antibody ligands have been extensively reviewed by 

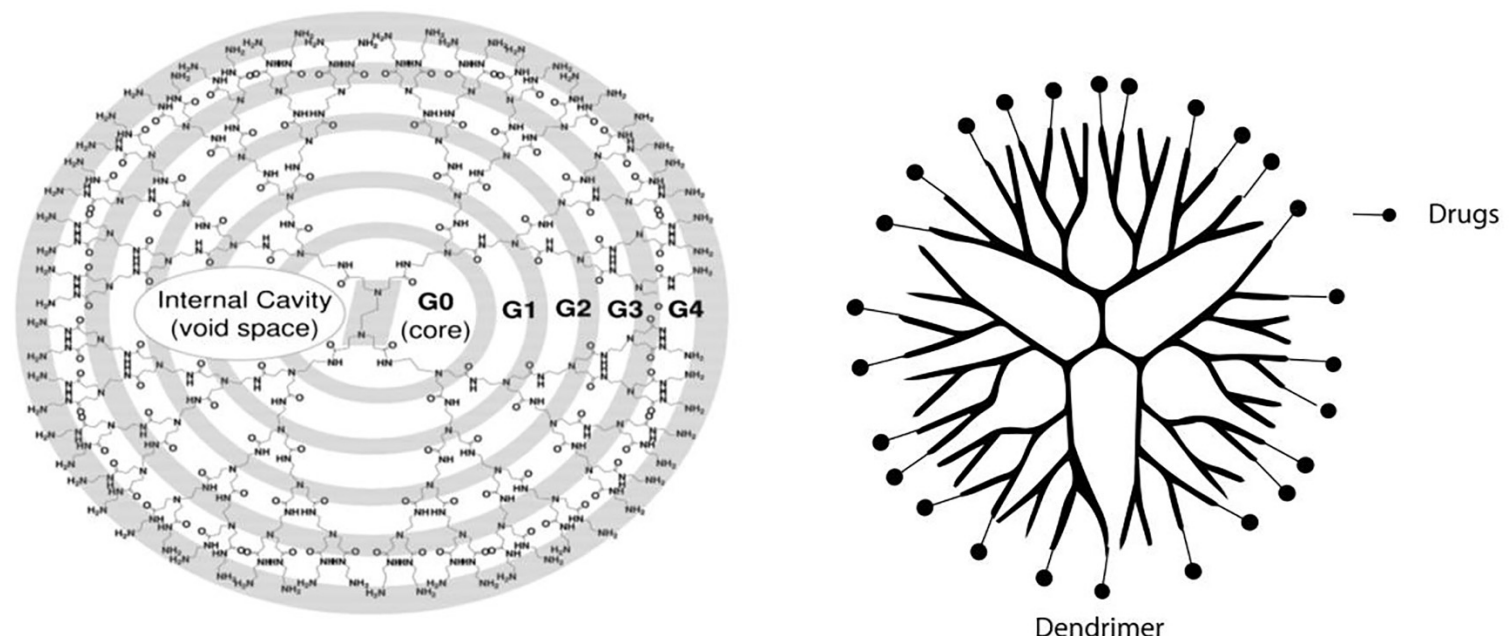

FIGURE 6 | Schematic representation of dendrimer. PAMAM-NH2 G0 to G4 dendrimer starts from an ethylenediamine core; the branches or arms were attached by exhaustive Michael addition to methyl acrylate followed by exhaustive aminolysis of the resulting methyl ester using ethylene diamine. Reprinted with permission (Abbasi et al., 2014).

Wang et al. (2017) Here we introduce drug delivery systems to different components of glomeruli.

\section{Drug Delivery Systems for Renal Glomeruli \\ Drug Delivery Systems for GBM and GEC}

GBM is a specialized extracellular matrix between GEC and podocyte, it consists mainly of laminin, type IV collagen, nidogen, heparan sulfate proteoglycan (Miner, 2012). And heparan sulfate proteoglycan contributed to the negative charge of the GBM and

TABLE 2 | Location of injury in glomerulonephritis.

\begin{tabular}{ll}
\hline Location & Disease \\
\hline Mesangial cell & IgA nephropathy \\
& Mesangioproliferative glomerulonephritis \\
& Class II lupus nephritis \\
& Diabetic nephropathy \\
Infection associated glomerulonephritis & Membranoproliferative glomerulonephritis \\
Endothelial cell & Class III and IV lupus nephritis \\
& Anti GBM disease \\
& Hemolytic uremic syndrome \\
& Vasculitis \\
Epithelial cell & Membranous nephropathy \\
& Minimal change nephropathy \\
& focal segmental glomerulosclerosis \\
& Class IV lupus nephritis
\end{tabular}

Table of Contents: Kidney disease has become a global health problem. And with nanotechnology, therapeutic agents can achieve selective accumulation at the kidney, and thus reduce the side effect and increase drug concentration on the diseased site. Here we summarized recent advances in nanoparticles designed for kidney targeted delivery according to the targeting sites. thus prevent albumin from being filtered (Kanwar et al., 1980). It is an important barrier limiting the targeted delivery of NPs.

\section{NPs Displaying Ligands}

The main approach to achieve GBM and GEC targeting is peptide and antibody ligands. Wang et al. created a kidneytargeted rhein ( $\mathrm{RH}$ )-loaded liponanoparticles (KLPPR) with polyethyleneimine-based cores and KTP-modified lipid layers. They use CLPVASC, an elastin-like polypeptide, to achieve glomerular endothelial cell barrier and basement membrane targeting (Figure 7; Wang et al., 2017). And the particle displayed excellent kidney-targeted distribution in diabetic nephropathy (Wang et al., 2019). Human monoclonal anti- $\alpha 3$ (IV) antibody, which can specifically bind to the non-collagenous-1 domain (NC1) of $\alpha 3(\mathrm{IV})$ collagen, can also be used as an antibody ligand to target drugs at glomeruli (Kvirkvelia et al., 2015, 2018).

\section{Drug Delivery Systems for Podocytes}

Podocytes cover the outer part of GBM, the slit between their foot processes is about 35-70 nm (Wang et al., 2017). And as podocytes are the final barrier of the glomerular filtration membrane, podocyte injury is typically related to proteinuria (Asanuma and Mundel, 2003).

\section{Ultrasmall NPs}

The nanocarriers have to pass through GBM $(6-10 \mathrm{~nm})$ before arriving at podocytes. Bruni et al. (2017) designed ultrasmall colloidal polymeric nanomaterials and try to target podocytes. The carrier is a polymer with/without a hydrophobic poly$\varepsilon$-caprolactone (PCL) core and a hydrophilic PEG shell. PEG Dexamethasone was encapsulated and repairment of damaged podocytes was observed in vitro (Bruni et al., 2017). However, though an elevated amount of the NP in urine was observed in vivo, the drug accumulation is higher in the liver and the spleen than in the kidney. 


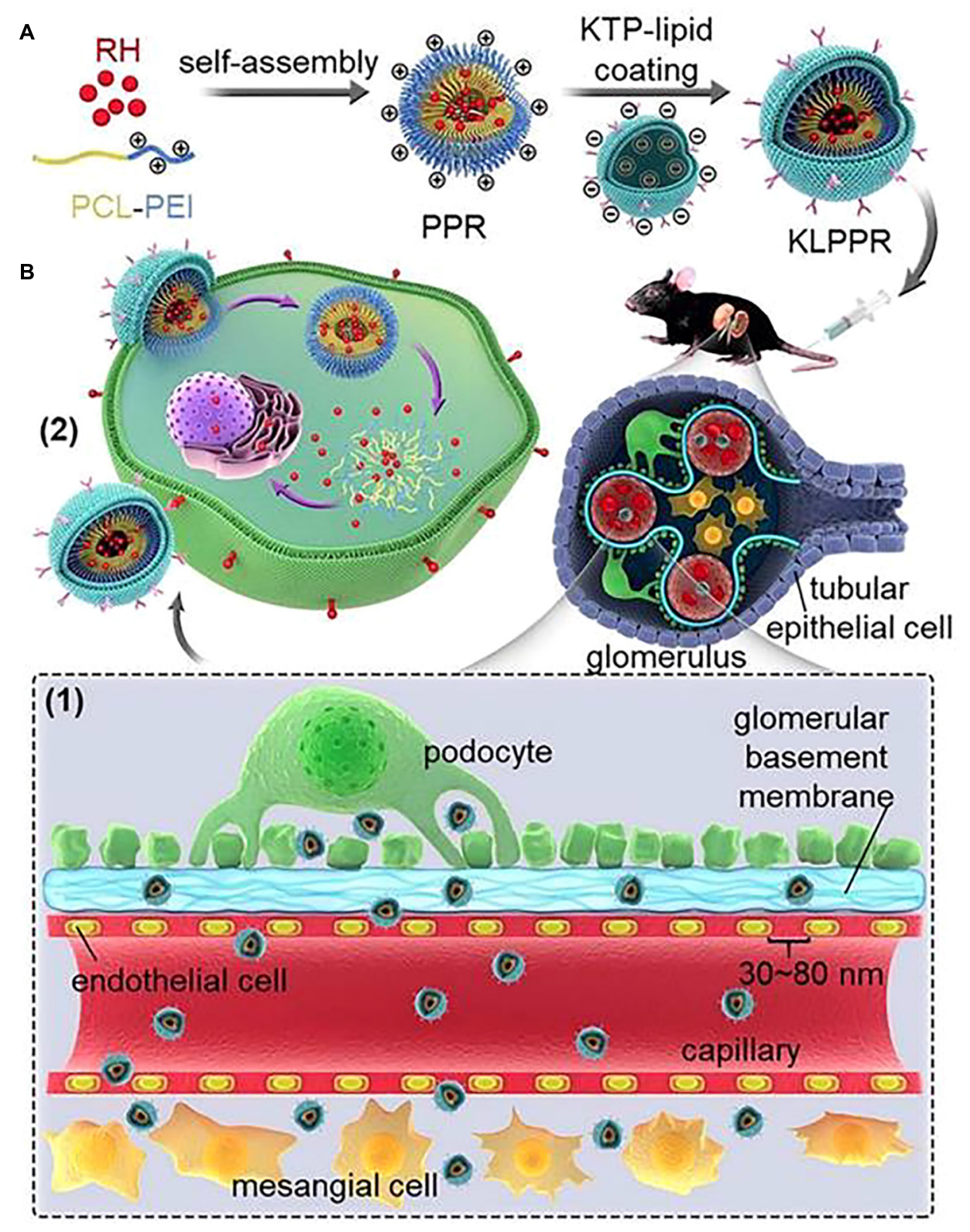

FIGURE 7 | KLPPR liponanoparticles for kidney-targeted drug delivery. (A) Kidney-targeted rhein (RH)-loaded liponanoparticles (KLPPR) with polyethyleneimine (PCL-PEI)-based cores and KTP-modified lipid layers. (B) Size control (30-80 nm) enables the particle to pass through the filtration membrane, and KTP decoration promotes cellular uptake and kidney retention of the particle. Reproduced with permission (Kvirkvelia et al., 2018).

\section{NPs Displaying Ligands}

Vascular adhesion molecule-1(VCAM-1) and cyclo-RGD peptide can be used as targeting ligands for podocytes. VCAM-1 is an inflammation-induced cell adhesion molecule, and the expression of VCAM is significantly upregulated in podocytes after stimulated by inflammatory cytokines. Visweswaran et al. (2015) constructed lipid-based nanocarriers called SAINT-O-Somes, and when displaying anti-VCAM1 antibody ligand, the NP can target podocytes in vitro. In vitro distribution of the drug is not investigated in this study. The cyclo-RGD peptide is an $\alpha v \beta 3$ integrin-specific ligand. $\alpha v \beta 3$ integrin is significantly higher in diseased nephrons. Poly(N-2hydroxypropyl) methacrylamide (PHMAM), PCL and liposome-based NPs with cyclo-RGD peptide was designed (Pollinger et al., 2012; Colombo et al., 2017). The NPs can bind to the $\alpha v \beta 3$ integrin receptor on podocytes in vitro. In vivo study in unilateral ureteral obstruction mice showed increased accumulation of RGD liposome in the fibrotic kidney (Zhou et al., 2021). When loaded with celastrol, inflammatory responses were ameliorated in glomeruli, while no obvious damages to other organs were observed. 
In fact, upregulated expression of $\alpha v \beta 3$ integrin or VCAM-1 is a common feature in various organs undergoing fibrosis, and it may not able to target specific cell types in vivo. But it provided a new approach to target diseased sites during kidney diseases.

\section{Drug Delivery Systems for Mesangial Cells}

Mesangial cells (MC) account for about $40 \%$ of glomerulus cells and are the main cellular component of mesangium. Mesangial cell injury is involved in various forms of glomerular diseases including immune-mediated glomerular diseases and metabolic diseases (Abboud, 2012). Especially, drugs including immunosuppressants targeting MCs may have great potential in improving the treatment of mesangial proliferative glomerulonephritis. To reach MCs, the NPs have to pass the glomerular endothelial barrier, whose fenestrae pore is sized 70-130 nm (Liu et al., 2019).

Theoretically, NPs sized less than this size can penetrate the pores and reach the mesangium. The size-associated accumulation is proved by PEGylated gold NPs. PEGylated gold NPs with diameters less than $100 \mathrm{~nm}$ can accumulate at the glomerular mesangium (Choi et al., 2011; Kamaly et al., 2016). The particles mainly accumulate at liver, spleen, and kidney, and the accumulation in liver and spleen was correlated with particle size. At the size of $75 \pm 25 \mathrm{~nm}$, maximum accumulation in kidney mesangium was reported.

\section{PLGA-PEG NPS}

Based on size selection, researchers constructed a $90 \mathrm{~nm}$ PLGAPEG NPs loaded with dexamethasone acetate, the NPs can deposit at MCs and the accumulation was achieved mainly through clathrin-dependent endocytosis (Li et al., 2019). By using the NPS, dexamethasone acetate is mainly distributed in the kidney. Its accumulation in the liver is significantly reduced comparing to traditional dexamethasone acetate solution and thus can reduce systemic side effects of the drug.

\section{Albumin Nanoparticles}

Albumin nanoparticles (ANs) produced by human serum albumin can be used as drug carriers for mesangial cells. They are biocompatible and biodegradable. Comparing with ANs of 75 or $130 \mathrm{~nm}$ size, ANs of $95 \mathrm{~nm}$ size showed better glomerular accumulation. The reason may lie in the mechanism of cellular internalization. Researchers found that cellular uptake of ANs is energy-dependent, and macropinocytosis, caveolae- and clathrin-mediated endocytosis participate in the process. All the three pathways mentioned contribute to the internalization of ANs sized $95 \mathrm{~nm}$ by the mesangial cells, while only one or two pathways are involved in the uptake of ANs sized 75 and $130 \mathrm{~nm}$. ANs loaded with celastrol (CLTAN) are prominent for the treatment of mesangioproliferative glomerulonephritis. Compared to traditional celastrol treatment, celastrol encapsulated in ANs showed improved ability to ameliorate renal injuries and reduced toxicity to brain, heart, and liver in animal models (Guo et al., 2017).

\section{NPs Displaying Ligands}

NPs coated with targeting antibodies are also proved to be able to target at MCs in animal models: anti-integrin $\alpha 8$ monoclonal antibodies for normal mice and mice with lupus glomerulonephritis (Scindia et al., 2008; Liu et al., 2019) and anti-Thy-1-membrane glycoprotein for IgA nephropathy in rats (Suana et al., 2011).

\section{Liposome}

Wang et al. (2020) designed a PEG-modified cationic liposome with octa-arginine (R8) coating and sized about $110 \mathrm{~nm}$. The liposomal nanoparticles are loaded with both p38 $\alpha$ MAPK and p65 siRNA, and they mainly accumulate at kidney with the highest uptake by MCs in mice models (Wang et al., 2020).

\section{Ultrasmall NPs}

A 2016 study showed that after intravenously injected, anionic ultrasmall quantum dot NPs $(\sim 3.7 \mathrm{~nm})$ can be gradually taken up by MCs up to 30 days (Liang et al., 2016), suggesting a possible way to design MC targeting ultrasmall NPs.

\section{THE CLEARANCE OF KIDNEY-SPECIFIC DELIVERY NANOMATERIALS}

Though many mechanisms may be involve in the clearance of kidney-targeted NPs, there are two main ways: directly filtered by the glomeruli and excreted into the urine, or eliminated through biodegradation.

Generally, NPs with a hydrodynamic diameter smaller than $5.5 \mathrm{~nm}$ can pass through the glomerular filtration membrane and excrete into the urine, and NPs larger than $6 \mathrm{~nm}$ can be cleared by the reticuloendothelial system (Choi et al., 2007; Alexis et al., 2008; Sadauskas et al., 2009; Tsoi et al., 2016; Du et al., 2017; Poon et al., 2020). However, studies showed that some quantum dot NPs with hydrodynamic diameters smaller than $4.5 \mathrm{~nm}$ may also accumulate at the kidney over 15-80 days (Su et al., 2011), and positively charged NPs can be cleared from the kidney faster than those with neutral or negative surface charge (Blanco et al., 2015). A study further analyzed the fate of ultrasmall meracaposuccinic acid capped quantum dots (MSA-QDs) with negative surface charge and PEI conjugated quantum dots (PEI-QDs) (Liang et al., 2016). At 30 min after administration, positively charged NPs (PEI-QDs) were filtered into urine while negatively charged NPs (MSA-QDs) were hardly observed in the urine. And the MSAQDs are found gradually accumulated in mesangial cells for more than 30 days.

And in another study, the clearance of a cationic, cyclodextrin-containing polymer (CDP)-based carrier was studied (Zuckerman et al., 2012). When loaded siRNA was fluorescently labeled with $\mathrm{Cy} 3$, the researchers found that after i.v. administration, the fluorescence signal was observed in glomerular cells within $10 \mathrm{~min}$, and then decreased markedly at $15 \mathrm{~min}$, and then ends up in the urine. However, a further study found that the NPs were disassembled at the GBM. Though siRNA was excreted into the urine, the NP carriers were deposited at the GBM. The researchers also found that some larger NPs also deposit at the endothelial cells of peri-tubule capillaries. The deposition pattern is also observed in pegylated gold NPs (Choi et al., 2011), so it is speculated as a generalized phenomenon for NP systems (Zuckerman et al., 2012), and further studies 
are needed to understand the long-term fate and toxicity of non-biodegradable kidney targeted NPs (Poon et al., 2019).

\section{LIMITATIONS AND FUTURE PERSPECTIVES}

Currently, many hybrids especially NP-based kidney-targeted drug delivery systems have been investigated. Though most of them are at an early stage, some of them achieved kidney-specific delivery, and comparing to traditional treatment method they showed markable therapeutic effect and significantly reduced side effect when loaded with drugs in diseased animal models. Still, work should be done to translate these achievements into clinical situations, and several limitations should be overcome. The first one is biosafety. As mentioned, the long-term fate and toxicity of non-biodegradable kidney-targeted NPs are unclear, and more detailed investigations should be done before clinical use. The second one is clinical effectiveness. Most research data are acquired from animals or even cells, and there is a huge gap between animal models (or cells) and actual patients. For example, some NPs displaying ligands or antibodies that depend on inflammatory responses in the kidney may face off-target effects in patients with systemic inflammation. The third one is

\section{REFERENCES}

Abbasi, E., Aval, S. F., Akbarzadeh, A., Milani, M., Nasrabadi, H. T., Joo, S. W., et al. (2014). Dendrimers: synthesis, applications, and properties. Nanoscale Res. Lett. 9:247. doi: 10.1186/1556-276X-9-247

Abboud, H. E. (2012). Mesangial cell biology. Exper. Cell Res. 318, 979-985. doi: 10.1016/j.yexcr.2012.02.025

Alexis, F., Pridgen, E., Molnar, L. K., and Farokhzad, O. C. (2008). Factors affecting the clearance and biodistribution of polymeric nanoparticles. Mol. Pharm. 5, 505-515. doi: 10.1021/mp800051m

Amin, M. L., Joo, J. Y., Yi, D. K., and An, S. S. (2015). Surface modification and local orientations of surface molecules in nanotherapeutics. J. Control Release 207, 131-142. doi: 10.1016/j.jconrel.2015.04.017

Asanuma, K., and Mundel, P. (2003). The role of podocytes in glomerular pathobiology. Clin. Exper. Nephrol. 7, 255-259. doi: 10.1007/s10157-0030259-6

Blanco, E., Shen, H., and Ferrari, M. (2015). Principles of nanoparticle design for overcoming biological barriers to drug delivery. Nat. Biotechnol. 33, 941-951. doi: $10.1038 /$ nbt.3330

Bruni, R., Possenti, P., Bordignon, C., Li, M., Ordanin, S., Messa, P., et al. (2017). Ultrasmall polymeric nanocarriers for drug delivery to podocytes in kidney glomerulus. J. Control. Release 255, 94-107. doi: 10.1016/j.jconrel.2017. 04.005

Centers for Disease Control and Prevention (2021). Chronic Kidney Disease Surveillance System Website. Available online at: https://nccd.cdc.gov/CKD (accessed March 15, 2021).

Chadban, S. J., and Atkins, R. C. (2005). Glomerulonephritis. Lancet 365, $1797-$ 1806. doi: 10.1016/S0140-6736(05)66583-X

Chauhan, V. P., Popović, Z., Chen, O., Cui, J., Fukumura, D., Bawendi, M. G., et al. (2011). Fluorescent nanorods and nanospheres for real-time in vivo probing of nanoparticle shape-dependent tumor penetration. Angew. Chem. 50, 11417-11420. doi: 10.1002/anie.201104449

Choi, C. H., Zuckerman, J. E., Webster, P., and Davis, M. E. (2011). Targeting kidney mesangium by nanoparticles of defined size. Proc. Natl. Acad. Sci. U.S.A. 108, 6656-6661. doi: 10.1073/pnas.1103573108

Choi, H. S., Ipe, B. I., Misra, P., Lee, J. H., Bawendi, M. G., and Frangioni, J. V. (2009). Tissue- and organ-selective biodistribution of NIR fluorescent quantum dots. Nano Lett. 9, 2354-2359. doi: 10.1021/nl900872r stableness in the manufacturing process. Producing a large scale of stable high-quality NPs is still difficult.

Biodegradable, non-toxic, non-immunogenic materials may prompt the translation from laboratory to clinical use. FDA has approved PLGA-PEG for human use. Hopefully, with the joint effort of nephrologists and technologists, these materials will provide novel approaches to kidney disease and finally apply them clinically.

\section{AUTHOR CONTRIBUTIONS}

$\mathrm{WL}, \mathrm{FH}$, and $\mathrm{YL}$ were responsible for the conception and design of the review, and revised the manuscript. XH and YM drafted the manuscript. All authors contributed to the article and approved the submitted version.

\section{FUNDING}

This work was supported by the grants from the National Key R\&D Program of China (2018YFC2000400) and the National Natural Science Foundation of China (81570605, 81670651, 81770674, and 81970573).

Choi, H. S., Liu, W., Misra, P., Tanaka, E., Zimmer, J. P., Itty Ipe, B., et al. (2007). Renal clearance of quantum dots. Nat. Biotechnol. 25, 1165-1170.

Christensen, E. I., and Birn, H. (2002). Megalin and cubilin: multifunctional endocytic receptors. Nat. Rev. Mol. Cell Biol. 3, 258-267. doi: 10.1038/nrm778

Colombo, C., Li, M., Watanabe, S., Messa, P., Edefonti, A., Montini, G., et al. (2017). Polymer nanoparticle engineering for podocyte repair: from in vitro models to new nanotherapeutics in kidney diseases. ACS Omega 2, 599-610. doi: 10.1021/acsomega.6b00423

Comper, W. D., and Glasgow, E. F. (1995). Charge selectivity in kidney ultrafiltration. Kidney Int. 47, 1242-1251. doi: 10.1038/ki.1995.178

Danhier, F., Ansorena, E., Silva, J. M., Coco, R., Le Breton, A., and Préat, V. (2012). PLGA-based nanoparticles: an overview of biomedical applications. J. Control. Release 161, 505-522. doi: 10.1016/j.jconrel.2012.01.043

Deng, X., Zeng, T., Li, J., Huang, C., Yu, M., Wang, X., et al. (2019). Kidneytargeted triptolide-encapsulated mesoscale nanoparticles for high-efficiency treatment of kidney injury. Biomater. Sci. 7, 5312-5323. doi: 10.1039/c9bm01 $290 \mathrm{~g}$

Dolman, M., Harmsen, S., Pieter, E., Sparidans, R., Lacombe, M., Szokol, B., et al. (2012a). Targeting of a platinum-bound sunitinib analog to renal proximal tubular cells. Intern. J. Nanomed. 7, 417-433. doi: 10.2147/ijn.s26485

Dolman, M., van Dorenmalen, K., Pieters, E., Sparidans, R., Lacombe, M., Szokol, B., et al. (2012b). Dendrimer-based macromolecular conjugate for the kidneydirected delivery of a multitargeted sunitinib analogue. Macromol. Biosci. 12, 93-103. doi: 10.1002/mabi.201100277

Dolman, M. E., Harmsen, S., Storm, G., Hennink, W. E., and Kok, R. J. (2010). Drug targeting to the kidney: advances in the active targeting of therapeutics to proximal tubular cells. Adv. Drug Deliv. Rev. 62, 1344-1357. doi: 10.1016/j. addr.2010.07.011

Du, B., Jiang, X., Das, A., Zhou, Q., Yu, M., Jin, R., et al. (2017). Glomerular barrier behaves as an atomically precise bandpass filter in a sub-nanometre regime. Nat. Nanotechnol. 12, 1096-1102. doi: 10.1038/nnano.2017.170

$\mathrm{Du}, \mathrm{B} ., \mathrm{Yu}, \mathrm{M}$., and Zheng, J. (2018). Transport and interactions of nanoparticles in the kidneys. Nat. Rev. Mater. 3, 358-374. doi: 10.1038/s41578-018-0038-3

Falke, L. L., Gholizadeh, S., Goldschmeding, R., Kok, R. J., and Nguyen, T. Q. (2015). Diverse origins of the myofibroblast-implications for kidney fibrosis. Nat. Rev. Nephrol. 11, 233-244. doi: 10.1038/nrneph.2014.246

Gao, S., Hein, S., Dagnaes-Hansen, F., Weyer, K., Yang, C., Nielsen, R., et al. (2014). Megalin-mediated specific uptake of chitosan/siRNA nanoparticles in 
mouse kidney proximal tubule epithelial cells enables AQP1 gene silencing. Theranostics 4, 1039-1051. doi: 10.7150/thno.7866

Geng, X., Zhang, M., Lai, X., Tan, L., Liu, J., Yu, M., et al. (2018). Smallsized cationic miRi-PCNPs selectively target the kidneys for high-efficiency antifibrosis treatment. Adv. Healthc. Mater. 7:e1800558. doi: 10.1002/adhm. 201800558

Gillies, E. R., and Frechet, J. M. (2005). Dendrimers and dendritic polymers in drug delivery. Drug Discov. Today 10, 35-43. doi: 10.1016/S1359-6446(04)03276-3

Grgic, I., Campanholle, G., Bijol, V., Wang, C., Sabbisetti, V. S., Ichimura, T., et al. (2012). Targeted proximal tubule injury triggers interstitial fibrosis and glomerulosclerosis. Kidney Int. 82, 172-183. doi: 10.1038/ki.2012.20

Guo, L., Luo, S., Du, Z., Zhou, M., Li, P., Fu, Y., et al. (2017). Targeted delivery of celastrol to mesangial cells is effective against mesangioproliferative glomerulonephritis. Nat. Commun. 8:878. doi: 10.1038/s41467-017-00834-8

Haraldsson, B., Nystrom, J., and Deen, W. M. (2008). Properties of the glomerular barrier and mechanisms of proteinuria. Physiol. Rev. 88, 451-487. doi: 10.1152/ physrev.00055.2006

Harris, J. M., and Chess, R. B. (2003). Effect of pegylation on pharmaceuticals. Nat. Rev. Drug Discov. 2, 214-221. doi: 10.1038/nrd1033

He, J., Chen, H., Zhou, W., Chen, M., Yao, Y., Zhang, Z., et al. (2020). Kidney targeted delivery of asiatic acid using a FITC labeled renal tubular-targeting peptide modified PLGA-PEG system. Intern. J. Pharm. 584:119455. doi: 10. 1016/j.ijpharm.2020.119455

He, Q., Zhang, Z., Gao, F., Li, Y., and Shi, J. (2011). In vivo biodistribution and urinary excretion of mesoporous silica nanoparticles: effects of particle size and PEGylation. Small 7, 271-280. doi: 10.1002/smll.201001459

Huang, D., and Wu, D. (2018). Biodegradable dendrimers for drug delivery. Mater. Sci. Eng. C Mater. Biol. Appl. 90, 713-727. doi: 10.1016/j.msec.2018.03.002

Huang, Y., Jiang, K., Zhang, X., and Chung, E. J. (2020). The effect of size, charge, and peptide ligand length on kidney targeting by small, organic nanoparticles. Bioeng. Transl. Med. 5:e10173. doi: 10.1002/btm2.10173

Janzer, M., Larbig, G., Kübelbeck, A., Wischnjow, A., Haberkorn, U., and Mier, W. (2016). Drug conjugation affects pharmacokinetics and specificity of kidneytargeted peptide carriers. Bioconjug. Chem. 27, 2441-2449. doi: 10.1021/acs. bioconjchem.6b00397

Jarad, G., and Miner, J. H. (2009). Update on the glomerular filtration barrier. Curr. Opin. Nephrol. Hyperten. 18, 226-232.

Jasim, D. A., Murphy, S., Newman, L., Mironov, A., Prestat, E., McCaffrey, J., et al. (2016). The effects of extensive glomerular filtration of thin graphene oxide sheets on kidney physiology. ACS Nano 10, 10753-10767. doi: 10.1021/acsnano. $6 \mathrm{~b} 03358$

Jiang, D., Ge, Z., Im, H.-J., England, C. G., Ni, D., Hou, J., et al. (2018). DNA origami nanostructures can exhibit preferential renal uptake and alleviate acute kidney injury. Nat. Biomed. Eng. 2, 865-877. doi: 10.1038/s41551-0180317-8

Kamaly, N., He, J. C., Ausiello, D. A., and Farokhzad, O. C. (2016). Nanomedicines for renal disease: current status and future applications. Nat. Rev. Nephrol. 12, 738-753. doi: 10.1038/nrneph.2016.156

Kang, H., Gravier, J., Bao, K., Wada, H., Lee, J. H., Baek, Y., et al. (2016). Renal clearable organic nanocarriers for bioimaging and drug delivery. Adv. Mater. 28, 8162-8168. doi: 10.1002/adma.201601101

Kanwar, Y. S., Linker, A., and Farquhar, M. G. (1980). Increased permeability of the glomerular basement membrane to ferritin after removal of glycosaminoglycans (heparan sulfate) by enzyme digestion. J. Cell Biol. 86, 688-693. doi: 10.1083/jcb.86.2.688

Katsumi, H., Takashima, R., Suzuki, H., Hirai, N., Matsuura, S., Kimura, H., et al. (2019). S-nitrosylated l-serine-modified dendrimer as a kidney-targeting nitric oxide donor for prevention of renal ischaemia/reperfusion injury. Free Radic. Res. 1-7. doi: 10.1080/10715762.2019.1697437

Kim, C. S., Mathew, A. P., Uthaman, S., Moon, M. J., Bae, E. H., Kim, S. W., et al. (2020). Glycol chitosan-based renal docking biopolymeric nanomicelles for site-specific delivery of the immunosuppressant. Carbohyd. Polym. 241:116255. doi: 10.1016/j.carbpol.2020.116255

Klibanov, A. L., Maruyama, K., Torchilin, V. P., and Huang, L. (1990). Amphipathic polyethyleneglycols effectively prolong the circulation time of liposomes. FEBS Lett. 268, 235-237. doi: 10.1016/0014-5793(90)81016-h

Kokkinopoulou, M., Simon, J., Landfester, K., Mailander, V., and Lieberwirth, I. (2017). Visualization of the protein corona: towards a biomolecular understanding of nanoparticle-cell-interactions. Nanoscale 9, 8858-8870. doi: $10.1039 / \mathrm{c} 7 \mathrm{nr} 02977 \mathrm{~b}$
Kravanja, G., Primožiè, M., Knez, Ž, and Leitgeb, M. (2019). Chitosan-based (Nano)materials for novel biomedical applications. Molecules 24:1960. doi: 10 . 3390/molecules24101960

Kvirkvelia, N., McMenamin, M., Gutierrez, V. I., Lasareishvili, B., and Madaio, M. P. (2015). Human anti-alpha3(IV)NC1 antibody drug conjugates target glomeruli to resolve nephritis. Am. J. Physiol. Renal. Physiol. 309, F680-F684. doi: 10.1152/ajprenal.00289.2015

Kvirkvelia, N., McMenamin, M., Warren, M., Jadeja, R. N., Kodeboyina, S. K., Sharma, A., et al. (2018). Kidney-targeted inhibition of protein kinase C-alpha ameliorates nephrotoxic nephritis with restoration of mitochondrial dysfunction. Kidney Int. 94, 280-291. doi: 10.1016/j.kint.2018. 01.032

Li, J., Zhang, C., He, W., Qiao, H., Chen, J., Wang, K., et al. (2017). Coordinationdriven assembly of catechol-modified chitosan for the kidney-specific delivery of salvianolic acid B to treat renal fibrosis. Biomater. Sci. 6, 179-188. doi: $10.1039 / \mathrm{c} 7 \mathrm{bm} 00811 \mathrm{~b}$

Li, S., Zeng, Y.-C., Peng, K., Liu, C., Zhang, Z.-R., and Zhang, L. (2019). Design and evaluation of glomerulus mesangium-targeted PEG-PLGA nanoparticles loaded with dexamethasone acetate. Acta Pharmacol. Sin. 40, 143-150. doi: 10.1038/s41401-018-0052-4

Liang, X., Wang, H., Zhu, Y., Zhang, R., Cogger, V. C., Liu, X., et al. (2016). Shortand Long-term tracking of anionic ultrasmall nanoparticles in kidney. ACS Nano 10, 387-395. doi: 10.1021/acsnano.5b05066

Lin, Y., Li, Y., Wang, X., Gong, T., Zhang, L., and Sun, X. (2013). Targeted drug delivery to renal proximal tubule epithelial cells mediated by 2 -glucosamine. J. Control. Release 167, 148-156. doi: 10.1016/j.jconrel.2013.02.001

Liu, C. P., Hu, Y., Lin, J. C., Fu, H. L., Lim, L. Y., and Yuan, Z. X. (2019). Targeting strategies for drug delivery to the kidney: from renal glomeruli to tubules. Med. Res. Rev. 39, 561-578. doi: 10.1002/med.21532

Liu, D., Shu, G., Jin, F., Qi, J., Xu, X., Du, Y., et al. (2020). ROS-responsive chitosan-SS31 prodrug for AKI therapy via rapid distribution in the kidney and long-term retention in the renal tubule. Sci. Adv. 6:eabb7422. doi: 10.1126/ sciadv.abb7422

Lu, Y., and Gu, Z. (2017). Kidney physiology: a size bandpass filter. Nat. Nanotechnol. 12, 1023-1025. doi: 10.1038/nnano.2017.200

Luo, J., Sun, J., Luo, X., Wei, Y., Zheng, H., Mu, C., et al. (2019). Low molecular weight chitosan-based conjugates for efficient Rhein oral delivery: synthesis, characterization, and pharmacokinetics. Drug Dev. Industr. Pharm. 45, 96-104. doi: 10.1080/03639045.2018.1522326

Matsuura, S., Katsumi, H., Suzuki, H., Hirai, N., Hayashi, H., Koshino, K., et al. (2018a). 1-Serine-modified polyamidoamine dendrimer as a highly potent renal targeting drug carrier. Proc. Natl. Acad. Sci. U.S.A. 115, 10511-10516. doi: $10.1073 /$ pnas. 1808168115

Matsuura, S., Katsumi, H., Suzuki, H., Hirai, N., Takashima, R., Morishita, M., et al. (2018b). 1-Cysteine and l-serine modified dendrimer with multiple reduced thiols as a kidney-targeting reactive oxygen species scavenger to prevent renal ischemia/reperfusion injury. Pharmaceutics 10:251. doi: 10.3390/ pharmaceutics10040251

Miner, J. (2012). The glomerular basement membrane. Exper. Cell Res. 318, 973-978. doi: 10.1016/j.yexcr.2012.02.031

Narayanan, D., Jayakumar, R., and Chennazhi, K. P. (2014). Versatile carboxymethyl chitin and chitosan nanomaterials: a review. Wiley Interdiscipl. Rev. Nanomed. Nanobiotechnol. 6, 574-598. doi: 10.1002/wnan.1301

Nielsen, R., Christensen, E. I., and Birn, H. (2016). Megalin and cubilin in proximal tubule protein reabsorption: from experimental models to human disease. Kidney Intern. 89, 58-67. doi: 10.1016/j.kint.2015.11.007

Oroojalian, F., Charbgoo, F., Hashemi, M., Amani, A., Yazdian-Robati, R., Mokhtarzadeh, A., et al. (2020). Recent advances in nanotechnology-based drug delivery systems for the kidney. J. Control Release 321, 442-462. doi: 10.1016/j. jconrel.2020.02.027

Oroojalian, F., Rezayan, A. H., Mehrnejad, F., Nia, A. H., Shier, W. T., Abnous, K., et al. (2017). Efficient megalin targeted delivery to renal proximal tubular cells mediated by modified-polymyxin B-polyethylenimine based nano-genecarriers. Mater. Sci. Eng. C Mater. Biol. Appl. 79, 770-782. doi: 10.1016/j.msec. 2017.05.068

Park, J.-H., von Maltzahn, G., Zhang, L., Schwartz, M. P., Ruoslahti, E., Bhatia, S. N., et al. (2008). Magnetic iron oxide nanoworms for tumor targeting and imaging. Adv. Mater. 20, 1630-1635.

Pavenstädt, H., Kriz, W., and Kretzler, M. (2003). Cell biology of the glomerular podocyte. Physiol. Rev. 83, 253-307. 
Pollinger, K., Hennig, R., Breunig, M., Tessmar, J., Ohlmann, A., Tamm, E., et al. (2012). Kidney podocytes as specific targets for cyclo(RGDfC)-modified nanoparticles. Small 8, 3368-3375. doi: 10.1002/smll.201200733

Poon, W., Kingston, B. R., Ouyang, B., Ngo, W., and Chan, W. C. W. (2020). A framework for designing delivery systems. Nat. Nanotechnol. 15, 819-829. doi: 10.1038/s41565-020-0759-5

Poon, W., Zhang, Y.-N., Ouyang, B., Kingston, B. R., Wu, J. L. Y., Wilhelm, S., et al. (2019). Elimination pathways of nanoparticles. ACS Nano 13, 5785-5798. doi: 10.1021/acsnano.9b01383

Qiao, H., Sun, M., Su, Z., Xie, Y., Chen, M., Zong, L., et al. (2014). Kidneyspecific drug delivery system for renal fibrosis based on coordination-driven assembly of catechol-derived chitosan. Biomaterials 35, 7157-7171. doi: 10 . 1016/j.biomaterials.2014.04.106

Ramos, A. M., González-Guerrero, C., Sanz, A., Sanchez-Niño, M. D., RodríguezOsorio, L., Martín-Cleary, C., et al. (2015). Designing drugs that combat kidney damage. Expert Opin. Drug Discov. 10, 541-556. doi: 10.1517/17460441.2015. 1033394

Richtering, W., Alberg, I., and Zentel, R. (2020). Nanoparticles in the biological context: surface morphology and protein corona formation. Small 16:2002162. doi: 10.1002/smll.202002162

Sadauskas, E., Danscher, G., Stoltenberg, M., Vogel, U., Larsen, A., and Wallin, H. (2009). Protracted elimination of gold nanoparticles from mouse liver. Nanomedicine 5, 162-169. doi: 10.1016/j.nano.2008.11. 002

Salvati, A., Pitek, A. S., Monopoli, M. P., Prapainop, K., Bombelli, F. B., Hristov, D. R., et al. (2013). Transferrin-functionalized nanoparticles lose their targeting capabilities when a biomolecule corona adsorbs on the surface. Nat. Nanotechnol. 8, 137-143. doi: 10.1038/nnano.2012.237

Scindia, Y., Deshmukh, U., Thimmalapura, P. R., and Bagavant, H. (2008). Antialpha8 integrin immunoliposomes in glomeruli of lupus-susceptible mice: a novel system for delivery of therapeutic agents to the renal glomerulus in systemic lupus erythematosus. Arthrit. Rheum. 58, 3884-3891. doi: 10.1002/art. 24026

Senapati, S., Mahanta, A. K., Kumar, S., and Maiti, P. (2018). Controlled drug delivery vehicles for cancer treatment and their performance. Signal Transd. Target. Therapy 3:7. doi: 10.1038/s41392-017-0004-3

Stead, S. O., Kireta, S., McInnes, S. J. P., Kette, F. D., Sivanathan, K. N., Kim, J., et al. (2018). Murine and non-human primate dendritic cell targeting nanoparticles for in vivo generation of regulatory T-Cells. ACS Nano 12, 6637-6647. doi: 10.1021/acsnano.8b01625

Su, Y., Peng, F., Jiang, Z., Zhong, Y., Lu, Y., Jiang, X., et al. (2011). In vivo distribution, pharmacokinetics, and toxicity of aqueous synthesized cadmium-containing quantum dots. Biomaterials 32, 5855-5862. doi: 10.1016/ j.biomaterials.2011.04.063

Suana, A. J., Tuffin, G., Frey, B. M., Knudsen, L., Muhlfeld, C., Rodder, S., et al. (2011). Single application of low-dose mycophenolate mofetilOX7-immunoliposomes ameliorates experimental mesangial proliferative glomerulonephritis. J. Pharmacol. Exp. Ther. 337, 411-422. doi: 10.1124/jpet. 110.176222

Sun, X., Yan, X., Jacobson, O., Sun, W., Wang, Z., Tong, X., et al. (2017). Improved tumor uptake by optimizing liposome based res blockade strategy. Theranostics 7, 319-328. doi: 10.7150/thno.18078

Tsoi, K. M., MacParland, S. A., Ma, X. Z., Spetzler, V. N., Echeverri, J., Ouyang, B., et al. (2016). Mechanism of hard-nanomaterial clearance by the liver. Nat. Mater. 15, 1212-1221. doi: 10.1038/nmat4718

Uchida, M., Maier, B., Waghwani, H. K., Selivanovitch, E., Pay, S. L., Avera, J., et al. (2019). The archaeal Dps nanocage targets kidney proximal tubules via glomerular filtration. J. Clin. Invest. 129, 3941-3951. doi: 10.1172/JCI12 7511

Visweswaran, G., Gholizadeh, S., Ruiters, M., Molema, G., Kok, R., and Kamps, J. (2015). Targeting Rapamycin to Podocytes using a vascular cell adhesion molecule-1 (VCAM-1)-harnessed SAINT-based lipid carrier system. PLoS One 10:e0138870. doi: 10.1371/journal.pone.0138870

Wang, G., Li, Q., Chen, D., Wu, B., Wu, Y., Tong, W., et al. (2019). Kidneytargeted rhein-loaded liponanoparticles for diabetic nephropathy therapy via size control and enhancement of renal cellular uptake. Theranostics 9, 61916208. doi: $10.7150 /$ thno. 37538
Wang, J., Masehi-Lano, J. J., and Chung, E. J. (2017). Peptide and antibody ligands for renal targeting: nanomedicine strategies for kidney disease. Biomat. Sci. 5, 1450-1459. doi: 10.1039/c7bm00271h

Wang, J., Poon, C., Chin, D., Milkowski, S., Lu, V., Hallows, K. R., et al. (2018). Design and in vivo characterization of kidney-targeting multimodal micelles for renal drug delivery. Nano Res. 11, 5584-5595. doi: 10.1007/s12274-018-2100-2

Wang, L., Zhang, Y., Li, Y., Chen, J., and Lin, W. (2021). Recent advances in engineered nanomaterials for acute kidney injury theranostics. Nano Res. 14, 920-933. doi: 10.1007/s12274-020-3067-3

Wang, Y., Wu, Q., Wang, J., Li, L., Sun, X., Zhang, Z., et al. (2020). Co-delivery of p38 $\alpha$ MAPK and p65 siRNA by novel liposomal glomerulus-targeting nano carriers for effective immunoglobulin a nephropathy treatment. J. Control. Release 320, 457-468. doi: 10.1016/j.jconrel.2020.01.024

Webster, A. C., Nagler, E. V., Morton, R. L., and Masson, P. (2017). Chronic kidney disease. Lancet 389, 1238-1252. doi: 10.1016/S0140-6736(16)32064-5

Williams, R. M., Jaimes, E. A., and Heller, D. A. (2016). Nanomedicines for kidney diseases. Kidney Intern. 90, 740-745. doi: 10.1016/j.kint.2016.03.041

Williams, R. M., Shah, J., Ng, B. D., Minton, D. R., Gudas, L. J., Park, C. Y., et al. (2015). Mesoscale nanoparticles selectively target the renal proximal tubule epithelium. Nano Lett. 15, 2358-2364. doi: 10.1021/nl504610d

Williams, R. M., Shah, J., Tian, H. S., Chen, X., Geissmann, F., Jaimes, E. A., et al. (2018). Selective nanoparticle targeting of the renal tubules. Hypertension 71, 87-94. doi: 10.1161/HYPERTENSIONAHA.117.09843

Wischnjow, A., Sarko, D., Janzer, M., Kaufman, C., Beijer, B., Brings, S., et al. (2016). Renal targeting: peptide-based drug delivery to proximal tubule cells. Bioconjug. Chem. 27, 1050-1057. doi: 10.1021/acs.bioconjchem.6b00057

Xu, Y., Qin, S., Niu, Y., Gong, T., Zhang, Z., and Fu, Y. (2020). Effect of fluid shear stress on the internalization of kidney-targeted delivery systems in renal tubular epithelial cells. Acta Pharm. Sin. B 10, 680-692. doi: 10.1016/j.apsb.2019.11.012

Yang, C., Nilsson, L., Cheema, M. U., Wang, Y., Frøkiaer, J., Gao, S., et al. (2015). Chitosan/siRNA nanoparticles targeting cyclooxygenase type 2 attenuate unilateral ureteral obstruction-induced kidney injury in mice. Theranostics 5 , 110-123. doi: 10.7150/thno.9717

Yu, H., Jin, F., Liu, D., Shu, G., Wang, X., Qi, J., et al. (2020). ROS-responsive nanodrug delivery system combining mitochondria-targeting ceria nanoparticles with atorvastatin for acute kidney injury. Theranostics 10, 2342-2357. doi: 10.7150/thno.40395

Yu, M., Zhou, C., Liu, L., Zhang, S., Sun, S., Hankins, J. D., et al. (2017). Interactions of Renal-clearable gold nanoparticles with tumor microenvironments: vasculature and acidity effects. Angew. Chem. Int. Edn. Engl. 56, 4314-4319. doi: 10.1002/anie.201612647

Zhang, D. X., Esser, L., Vasan, R. B., Thissen, H., and Voelcker, N. H. (2019). Porous silicon nanomaterials: recent advances in surface engineering for controlled drug-delivery applications. Nanomedicine 14, 3213-3230. doi: 10.2217/nnm2019-0167

Zhao, J. (2019). Mesangial cells and renal fibrosis. Adv. Exper. Med. Biol. 1165, 165-194. doi: 10.1007/978-981-13-8871-2_9

Zhou, J., Li, R., Zhang, J., Liu, Q., Wu, T., Tang, Q., et al. (2021). Targeting interstitial myofibroblast-expressed integrin alphavbeta3 alleviates renal fibrosis. Mol. Pharm. 18, 1373-1385. doi: 10.1021/acs.molpharmaceut. $0 \mathrm{c} 01182$

Zhou, P., Sun, X., and Zhang, Z. (2014). Kidney-targeted drug delivery systems. Acta Pharm. Sin. B 4, 37-42. doi: 10.1016/j.apsb.2013.12.005

Zuckerman, J. E., Choi, C. H., Han, H., and Davis, M. E. (2012). Polycation-siRNA nanoparticles can disassemble at the kidney glomerular basement membrane. Proc. Natl. Acad. Sci. U.S.A. 109, 3137-3142. doi: 10.1073/pnas.1200718109

Conflict of Interest: The authors declare that the research was conducted in the absence of any commercial or financial relationships that could be construed as a potential conflict of interest.

Copyright (c) 2021 Huang, Ma, Li, Han and Lin. This is an open-access article distributed under the terms of the Creative Commons Attribution License (CC BY). The use, distribution or reproduction in other forums is permitted, provided the original author(s) and the copyright owner(s) are credited and that the original publication in this journal is cited, in accordance with accepted academic practice. No use, distribution or reproduction is permitted which does not comply with these terms. 